\title{
The secretory senescence of the senses of smell and taste
}

\author{
Krizia Piccininni', Francesco Barbara'1, Carlo De Luca², Andrea Mazzatenta ${ }^{3}$, \\ Luigi De Luca², Giulia De Luca², Carmelo Zappone ${ }^{4}$, Silvana Ciccarone ${ }^{1}$ \\ ${ }^{1}$ Department of Otorhinolaryngology "Mons. Dimiccoli” Hospital, Barletta, Italy; \\ 2 "Fisioter srl" Clinical Centre, San Salvo, Italy; ${ }^{3}$ Department of Neuroscience, Imaging and Clinical \\ Science, University of Pescara-Chieti, Italy; ${ }^{4}$ "Casa di Cura Liotti", Clinical Centre, Perugia, Italy
}

Aging is a progressive and multifaceted event, which involves all the cells and organs of the human body. In this chapter we will try to analyze how the senses of smell and taste change with age. Anatomical and physiological modifications of the nose and salivary glands will be described, as well as changes in structures of the Central Nervous System and neurochemical processes that underlie these two senses.

Finally, we will discuss the effect of many senile age drugs and chemo-radiotherapy on the perception of smell and taste, as well as the impact of chronical diseases on these senses.

Key words: aging, smell, taste, nose, salivary glands, drugs, chemotherapy, radiotherapy

\section{THE SECRETORY SENESCENCE OF SMELL}

Received: March 30, 2020

Accepted: June 10, 2020

\section{Correspondence \\ Krizia Piccininni \\ U.O.C. di Otorinolaringoiatria, Ospedale "Mons. \\ Dimiccoli" Hospital, Barletta, viale Ippocrate 15, \\ 72121 Barletta, Italy \\ E-mail: kriziap@hotmail.it}

\section{Conflict of interest}

The Authors declare no conflict of interest

How to cite this article: Piccininni $\mathrm{K}$, Barbara F, De Luca C, et al. The secretory senescence of the senses of smell and taste. Journal of Gerontology and Geriatrics 2020;68:91-98. https://doi. org/10.36150/2499-6564-486

(C) Copyright by Società Italiana di Gerontologia e Geriatria (SIGG)

\section{(c) (1) (3) $€$}

\section{OPEN ACCESS}

This is an open access article distributed in accordance with the CC-BY-NC-ND (Creative Commons Attribution-NonCommercial-NoDerivatives 4.0 International) license. The article can be used by giving appropriate credit and mentioning the license, but only for non-commercial purposes and only in the original version. For further information: https://creativecommons.org/licenses/by-nc-nd/4.0/deed.en
Aging is a physiological process, which has been widely studied for many human body systems and in different species ${ }^{1}$. As concerns the sense of smell, researchers have not developed a unified model to explain the agerelated modifications ${ }^{2}$. The term "presbynasalis" has been introduced to describe the aging process of the nose and its functions.

The nose is a dynamic organ. Different conditions can influence the air flow pattern, modifying the nasal turbinate engorgement and the nasal secretory activity: air temperature and humidity, environmental factors (allergens, chemical molecules, infectious agents, air pollution, tobacco smoke), as well as physical activity and psychological stress.

\section{ANATOMICAL AND PHYSIOLOGICAL CHANGES}

Anatomical age-related modifications have been well documented. Cartilage becomes thinner and less elastic with age; in addition, the facial muscles weaken and undergo atrophy. As a result, the nose tip is not well supported and tends to fall. A progressive retraction of the columella is also observed.

Physiological changes, such as thickening of the nasal secretions and reduced ciliary-beat frequency can adversely affect the airflow. In 2001, Ho et al. studied the nasal mucosa of a group of healthy volunteers aged from 11 to 90 years, evaluating the muco-ciliary clearance time, the ciliarybeat frequency, and the ultrastructure of respiratory cilia. A significantly slower ciliary-beat frequency and longer muco-ciliary clearance time were observed in the subjects older than 40 years. These changes may help to 
explain the frequent occurrence of respiratory infection in the elderly ${ }^{3}$.

The anatomical and physiological modifications mentioned above are more accentuated in patients with chronic rhinosinusitis and nasal polyposis, conditions that seem to prevail in older age 4 .

In 2007, a prospective study evaluated the objective and subjective surgical outcomes in patients who underwent endoscopic surgery to treat chronic rhinosinusitis with nasal polyposis (CRSwNP), finding better postoperative results in the geriatric group than in the paediatric and adult groups. The authors assess that the decreased rate of mucosal regeneration, typical of the elderly, can play a role in preventing polyp recurrence; however, in these patients a longer healing period is required ${ }^{5}$. In a 2012 study, Hong et al. assert that the impairment of epithelial barrier function persists and may worsen with age; this may contribute to explain the increasing incidence of nasal polyposis in the elderly population. Olfactory dysfunction is common in CRSwNP patients; in 2019, Gelardi et al. suggest that the clinical-cytological grading (CCG) may be useful in the work-up of CRSwNP patients, with a CCG score $>4$, suggesting an olfactory impairment ${ }^{6}$.

Changes in the composition of the nasal mucus can result in olfactory dysfunction, as the odorous particles need to be dissolved to interact with the olfactory receptors. A clear, anterior rhinorrhoea is commonly observed in older adults; it is widely known as "senile rhinorrhoea". In a 2015 study, Rodriguez et al. found that this condition is significantly more frequent and more intense in the older subjects; the incidence of rhinorrhoea was independent from sex. Subjects who complained of a more frequent nasal drip appeared to be more bothered by this condition and, therefore, more interested in pursuing therapy. The aetiology of rhinorrhoea of aging is not well known. With aging, the activity of the sympathetic system increases; however, the alpha-receptors and beta-receptors are less sensitive. This could result in a decreased sympathetic tone. A continuous parasympathetic stimulation leads to an increased glandular secretion in the nose ${ }^{\text {. }}$.

On the other hand, it is not uncommon to observe a reduction of the aqueous component of the nasal mucus in elderly individuals. Increased viscosity, reduced muco-ciliary clearance capacity and structural changes in the blood vessel wall may impair the air warming and the mucosal moisturizing processes, leading to nasal dryness and irritation ${ }^{8}$.

\section{Changes in the olfactory epithelium AND THE OLFACTORY BULB}

The mucosal blood flow decreases with age; thus, the nasal epithelium becomes atrophic, thinner, and less elastic ${ }^{8}$. Changes are also evident within the cribriform plate: aging leads to the progressive occlusion of the foramina, thus the olfactory cell axons can be damaged by gradual compression; this may result in cell necrosis. There is evidence that the density of receptor cells in the olfactory epithelium decreases with age; the olfactory mucosa is gradually replaced with respiratory epithelium. Studies performed on rats suggest that the mitotic activity of olfactory receptor cells decreases with age. A schematic drawing of the olfactory system can be seen in figure 1.

Other factors determining olfactory dysfunction are a progressive impairment of the immunologic and enzymatic defence mechanisms and the cumulative effect of the exposition to environmental factors (chemical agents, air pollution, tobacco smoke, allergens, etc.) throughout the lifespan.

Histological studies performed on autopsied olfactory bulbs found a global thinning and a reduction in the number of glomeruli in older subjects. Bulbar modifications seem to be consequent to the epithelial modifications; within the glomeruli, an increased number of synapses per olfactory cell was documented in older rats, thus suggesting a compensatory reaction.

Age-related volume reduction in human olfactory bulb was documented in vivo using magnetic resonance (MR) imaging. However, these findings cannot be considered as specific for aging, as they can be found also in cigarette smokers and other conditions such as congenital anosmia, chronic sinusitis, nasal polyposis, as well as in neurodegenerative diseases, acute depression, epilepsy and multiple sclerosis. This suggests that olfactory bulb volume may be a non-specific indicator of the olfactory function ${ }^{9}$.

\section{Changes in the Central Nervous System}

It is well known that aging leads to a reduction in brain weight, thickness of the cerebral cortex, and synaptic activity. The brain processing of olfactory information is also compromised. Functional imaging studies, performed with MR and positron emission tomography, documented a decreased activity in central olfactory pathways after odorous stimulation in elderly individuals. All these modifications contribute to explain the deterioration of the sense of smell over the years ${ }^{9}$.

Impaired olfactory function is a peculiar feature of two Lewy body disorders: dementia with Lewy bodies and Lewy body Parkinsonism. For both disorders, neurons of the olfactory system are among the first to present the typical histopathological changes. Furthermore, Lewy bodies were observed in the brains of old subjects who died without Parkinson's disease or dementia; this may suggest a possible preclinical stage in Lewy body disorders. 


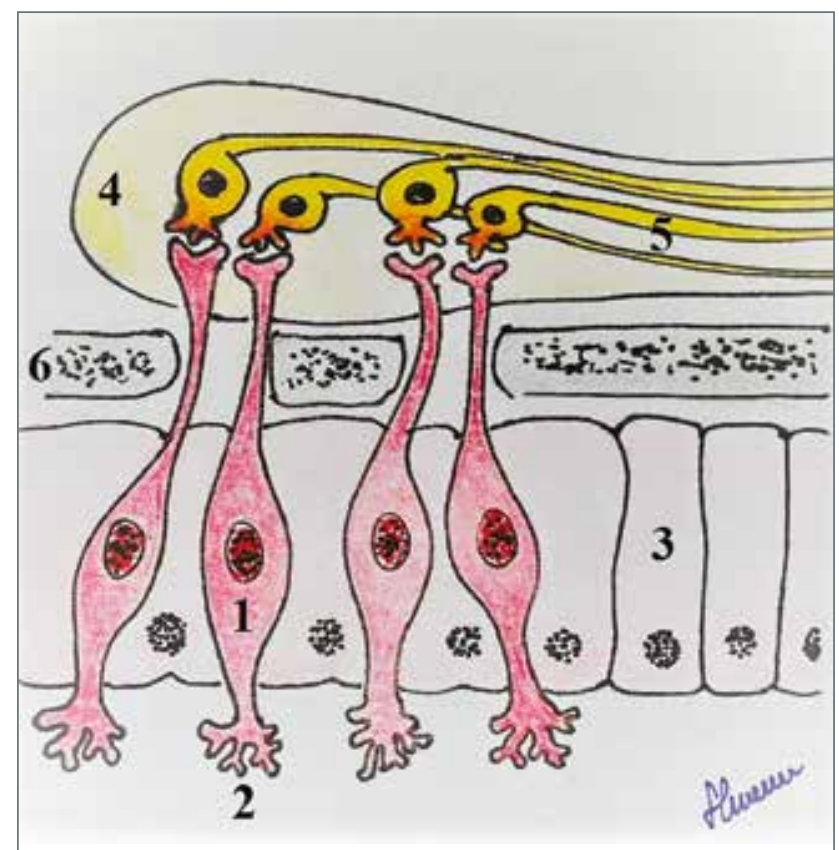

1. olfactory receptor cell; 2. cilia; 3 . columnar epithelial cell; 4. olfactory bulb; 5. olfactory nerve fibers; 6 . cribriform plate.

Figure 1. Synaptic connections in the olfactory bulb.

In 2011, Wilson et al. investigated the correlation between the age-related olfactory dysfunction and the autoptic findings of Lewy bodies in different brain regions. They tested the ability to identify familiar odours in more than 200 elderly individuals. Upon death, Lewy bodies were found in the brain of those with olfaction dysfunction. Although impaired olfaction has been recognized as a symptom of Lewy body disorders, to date the contribution of Lewy bodies to olfactory dysfunction in people without Lewy body disorders is not well understood. The Authors suggest that olfactory tests may be useful to the early detection of Lewy body disorders, in addition to clinical examination, neuroimaging studies and biologic markers ${ }^{10}$.

\section{Age-ReLATEd NeUROCHEMICAL CHANGeS}

With age, important neurochemical changes have been observed in the brain, concerning numerous enzymes, neurotransmitters, and neuromodulator systems. Physiologically, most of the age-related neurochemical decline occur before the age of 60 years; it means that, in case of neurodegenerative diseases, significant neurochemical changes have still happened at their onset. Among the neurotransmitters, acetylcholine is intimately involved in the modulation of olfactory function, as it plays a role in the synchronization of odour-induced activity from the olfactory bulb to the piriform cortex and facilitates odour learning and memorization.
Cholinergic neurons have a double function. On the one hand, they directly modulate neural activity within the olfactory bulb; on the other hand, with the contribution of other neurotransmitters, they tonically inhibit the activity of microglial cells, which are the innate immune effector cells of the Central Nervous System (CNS). Alterations in such modulation can lead to the release of inhibition on the microglial cells, resulting in the production of inflammatory mediators and neuronal damage ${ }^{9}$.

\section{Genetic of AGE-RELATED OLFACTORY DYSFUnCtion}

A number of genes have been found to contribute to the age-related decline in odour identification.

In 2010, Hedner et al. studied the impact of the brainderived neurotrophic factor (BDNF) val66met polymorphism on age-related olfactory decline. BDNF is a neurotrophin family growth factor, which supports neuronal survival, transmission, and synaptic plasticity in the CNS. The carriers of the val homozygote allele exhibit a marked age-related impairment in olfactory function, whereas the val66met polymorphism seems to be protective against accelerated olfactory decline in elderly ${ }^{11}$.

Calhoun-Haney and Murphy examined the olfactory function and the cognitive status in non-demented elderly individuals with the epsilon4 allele of the human apolipoprotein E gene (epsilon4+) ${ }^{12}$. Apolipoprotein E is a plasma protein involved in lipid transport; its allelic variant epsilon4 has been associated with late onset familial and sporadic Alzheimer's disease ${ }^{13}$.

When retested after four years, the epsilon4+ subjects exhibited a significant decline in odour identification but not in odour threshold, picture identification or global cognitive status. Authors relate these findings to the impairment of the cortical areas associated with semantic memory for odours ${ }^{12}$.

\section{QUANTIFICATION OF SMELL LOSS}

The olfactory perception can be studied through psychophysical tests (e.g., tests of odour detection, identification, discrimination, memory, and suprathreshold intensity), electrophysiological tests (e.g., odour eventrelated potentials), and psychophysiological tests (e.g., odour-related changes in heart rate and respiration) ${ }^{9}$. Olfactory tests can be classified as subjective tests, based on the subjective response of the patient, or objective tests, that record physiological changes after olfactory stimulation.

The first steps towards the olfactometry were moved by the physiologist Valentin in 1842, and, fifty years later, by Passy who investigated the structure of the odorants. At the end of the nineteenth century Zwaardemaker, famous for his statement "we live in a world of odour like the world of sight and sound", designed a simple instrument to measure the olfactory threshold, which 


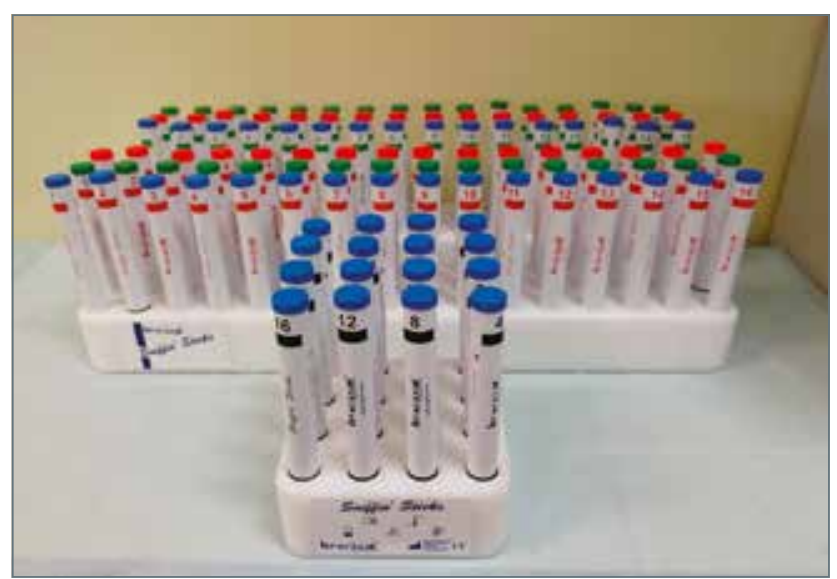

Figure 2. The Sniffin' Sticks Test.

consisted of a short kaoline tube with some odorous capsules inside.

The greatest development in olfactory testing occurred in the last thirty years. For many years, the most used test has been the University of Pennsylvania Smell Identification Test (UPSIT), conceived by Doty et al. in 1984. It consists of 40 microencapsulated odours ("scratch and sniff") and can be self-administered. The result is normalized with respect to the patient's age and gender; finally, the patient is categorized as normosmic, anosmic or hyposmic.

In 1988, Cain et al. introduced the Connecticut Chemosensory Clinical Research Center Test (CCCRCT), which consisted of a threshold test and an identification test.

In order to overcome the cultural differences and make the test available also in Europe, in 1996 Doty modified the UPSIT, changing the odorous stimuli according to the tradition and culture of different populations. Thus, the Cross-Cultural Smell Identification Test (CC-SIT) was designed; it consists of 12 odours that the patient should identify, choosing between different options.

In 1997, Hummel introduced in Europe the Sniffin' Sticks (SS) (figure 2) test; it is a psychophysical test that allows a semi-objective assessment of the patient's olfactory performance. The SS test, unlike UPSIT, cannot be self-administered. It requires particular felt pens, with the tips impregnated with odorant fluid. Each pen must be submitted only once, for 3 or 4 seconds, positioned about $2 \mathrm{~cm}$ from the edge of the nostril. The SS test consists of 3 subtests: the threshold test, the identification test and the odour discrimination test. It results in 4 scores: threshold score (T), discrimination score (D), identification score (I) and global olfactory score (TDI), which is the sum of the previous three ${ }^{14}$.

Nowadays, Mazzatenta and colleagues have developed several systems to objectively investigate the olfactory perception using the Olfactory Event-Related Potentials and the Exhaled Organic Volatile Compounds. These tests return a crucial link between neurophysiology of perception and metabolic physiology ${ }^{15-19}$.

\section{AGE-RELATED OLFACTORY DYSFUNCTION AND QUALITY OF LIFE}

It has been documented that $50 \%$ of patients aged between 65 and 80 years exhibits smell impairment; the percentage rises to $75 \%$ if a population older than 80 years is considered ${ }^{9}$. The most worrying data emerging from a 2002 study is that almost all the subjects suffering from olfactory disorders are not aware of it: only $9.5 \%$ complained of smell changes in self-reporting tests ${ }^{20}$.

Undoubtedly, olfactory impairment compromises the quality of life. First of all, subjects complain of a decreased taste ability, as the flavour is perceived thanks to the senses of taste and smell. The lack of the hedonistic component may contribute to malnutrition in the elderly.

Another fundamental aspect is a reduced perception of danger. Recent studies have shown that among patients with olfactory deficits, $37 \%$ experienced a dangerous smell-related event, such as a gas leak or food burned while cooking. Among individuals with normal smell, the percentage drops to $19 \%{ }^{9}$.

\section{THE SECRETORY SENESCENCE OF TASTE}

The sense of taste originates from the interaction of molecules, present in food or drinks, with the taste sensory cells, placed in the surface of the tongue, but also in the palate, pharynx, and larynx. The five main flavours (salty, acid, sweet, bitter and umami) are induced by chemical stimuli; each one is detected by the gustatory cells with a different molecular mechanism of transduction. The end organ of the sense of taste is the gustatory bud, a spherical cluster of receptor cells located in the epithelium of the tongue (figure 3). The taste cells are renewed often, with an average life of two weeks, and are regenerated by basal cells. Taste is closely related to the sense of smell. Food and drinks also stimulate the sense of smell by means of volatile molecules that reach the olfactory epithelium through the nasopharynx.

Saliva is the first secretion produced by the gastrointestinal system. Thanks to its lubricating and rheological properties, it participates to oral processing of food, it allows swallowing, facilitates speech, and has a role in food flavour perception. Indeed, in order to reach the taste receptors, all non-volatile food components need to be dissolved in the saliva. Furthermore, saliva secretion ensures continuous hydration of the mouth and have an antibacterial function thanks to lysozyme, lactoferrin, peroxidase systems, slgA, histatins and 


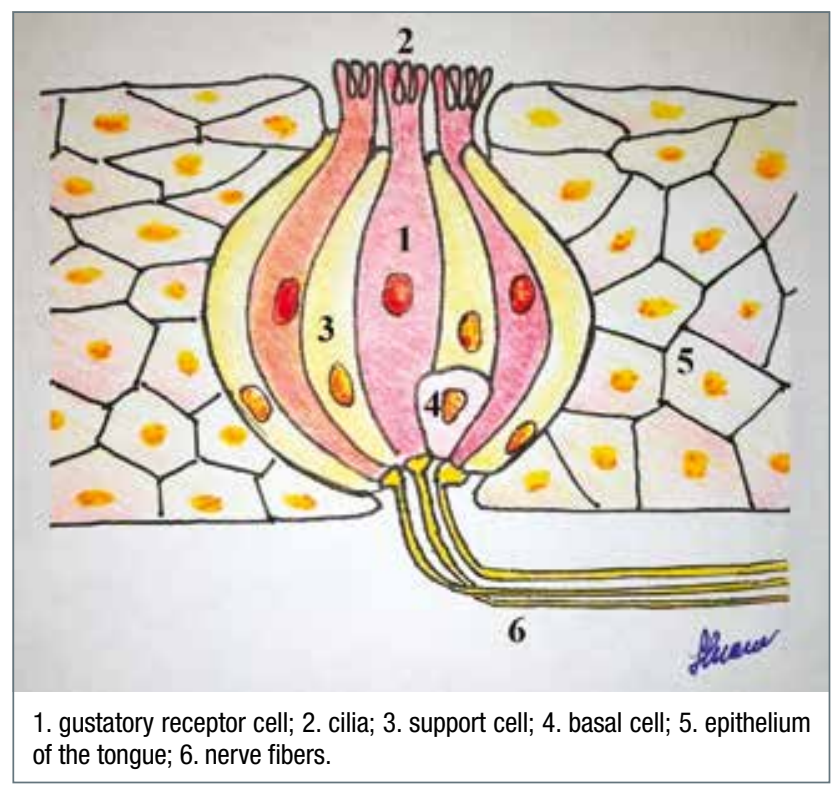

Figure 3. The gustatory bud.

mucins contained inside.

The major salivary glands - parotid, submandibular and sublingual glands - produce $95 \%$ of saliva. The remaining $5 \%$ is produced by the minor salivary glands, distributed in the palate, cheeks, tongue, and lips. Salivary glands secrete about 1-1.5 liters of saliva per day in adults.

Saliva is primarily produced in the acinar cells, which can be distinguished in serous cells - secreting digestive enzymes such as ptyalin - and mucous cells producing mucin, which consists of glycoproteins of various molecular weight. Acinar cells determine the type of secretion in the different glands; the parotid glands are serous secretion glands; minor salivary glands have mucous secretion; sublingual and submandibular glands have mixed serous and mucous secretion ${ }^{21}$.

Salivary glands activity is regulated by the Autonomic Nervous System (ANS). Both parasympathetic and sympathetic systems stimulate salivary secretion, although the parasympathetic system has a greater action.

Ageing affects the ability to taste for several reasons. Physiological changes in salivary glands lead to their progressive hypofunction. Several systemic diseases such as diabetes, hypertension and Sjogren's syndrome, as well as drugs, radiotherapy, and chemotherapy can lead to salivary gland dysfunction since these factors can compromise blood perfusion and are responsible for histological gland damage. Other causes of the age-related taste loss are a decline in cognitive function, a decreased number of taste and smell receptors, a reduced gland stimulation by the ANS. All these factors, in addiction to impaired chewing ability due to teeth loss, may result in reduced nutrient intake and malnutrition.

\section{HISTOLOGICAL SALIVARY GLANDS MODIFICATIONS}

In parotid and submandibular glands ageing seems to lead to atrophy of the functional parenchyma, which is replaced with connective tissue and fat. The number of ducts remains constant. Conversely, the minor salivary glands do not exhibit fatty degeneration; atrophy of the parenchymal component is replaced with an increase in the fibrovascular component and in the number of ducts.

These histological changes result in overall salivary gland hypofunction ${ }^{21}$.

\section{ChANGes In SALIVARY SECRETION}

Ageing alters both quantity (flow rate) and quality (ion and protein composition, rheology, tribology) of salivary secretions.

Several studies investigated the age-related changes in salivary flow rate. As reported by Xu et al. in their 2018 review, the findings are inconsistent, probably due to the wide variability in study design and saliva collection method among the different centers. Interestingly, a 2015 meta-analysis of 47 published reports, relating aging to salivary secretion, revealed that both unstimulated and stimulated average saliva flow rates were significantly lower in older adults than younger. Such a decrease seems to result from a lower activity of submandibular and sublingual glands, as parotid and minor salivary gland flow rates did not appear to be significantly lower.

Researchers agree that the use of multiple medications in the elderly population, such as antidepressants, diuretics, analgesics, antihistamines, antihypertensives and antianxiety drugs, does not fully explain the differences in salivary flow rates between younger and older adults. The determinant factors seem to be the agerelated histological modifications in salivary glands, as described above. Such a decrease in salivary flow rate indirectly influences the quality of saliva ${ }^{21}$.

\section{Changes in salivary composition}

Saliva is essentially made up of water (99.5\%), electrolytes, organic components, and enzymes.

Studies on salivary composition in healthy elderly people are relatively scarce, since most of the works concerns patients with burning mouth syndrome, Sjögren's Syndrome, or patients who underwent radiotherapy ${ }^{21}$. In a 2005 study, Nagler and Hershkovich found a significant increase in concentration of both organic and inorganic salivary components in healthy elderly individuals as compared to young population; they related this data to the age-dependent reduction of the salivary flow rate. As concerns the organic components, in addition to the salivary concentration, they also measured the total amount secreted into the oral cavity, concluding 
that in the elderly the total values of most salivary components decrease parallel to the salivary flow rate 22 . In 2014, Nassar et al. found a decrease in salivary calcium level in elderly people compared to young ${ }^{23}$. Conversely, Sevon et al. reported elevated levels of salivary calcium in elderly women, with a peak at around the age of 50 years, compared to that of young women. In authors' opinion, this data can be related to a lower bone density in elderly women ${ }^{24}$.

However, since these studies do not use standardized age categories, the variety of the age ranges could have a significative impact on the results ${ }^{21}$; furthermore, Sevon's study regards women only, instead the other studies examine both sexes.

Interestingly, in literature there is consensus about the reduction of salivary mucin concentration with aging ${ }^{21}$. Among mucins, the membrane-associated and the secreted soluble mucins can be distinguished. The first (MUC1, MUC3, MUC4, MUC12) form an immobile pellicle on the apical surface of epithelial cells and act as a barrier. The others (MUC2, MUC5A, MUC5B, MUC6, MUC7) form a mobile salivary film. A decrease in MUC1 and MUC2 salivary secretion has been reported in elderly subjects. Mucins provide an efficient barrier against the penetration of injurious substances into the epithelial cells as well as dryness. The lack of mucins may significantly affect oral health in elderly population ${ }^{22}$. Studies on dry mouth patients' saliva show lower levels of MUC5B and MUC7 that are responsible for altered rheological properties and for a reduced mucosal hydration ${ }^{21}$.

In healthy elderly subjects, a lower lactoferrin and peroxidase activity has been reported, as well as reduction of slgA, kallikrein and lysozyme, which result in weakened immunological and enzymatic defense ${ }^{25}$.

As concerns the salivary bicarbonate, the findings are not consistent. A 2003 study investigated the concentration of electrolytes in stimulated whole saliva in individuals with hyposalivation; lower levels of bicarbonate, the main salivary buffer, were reported in elderly people ${ }^{26}$. On the other hand, in their 2014 study Nassar et al. assessed that the salivary buffering capacity is not related to age. As most of the salivary bicarbonate is secreted by the parotid gland, the parotid gland function seems to be not prejudiced by aging ${ }^{23}$.

A lower salivary concentration of basic fibroblast growth factor (bFGF) has been reported in elderly subjects. bFGF is involved in wound healing and tissue repair. The salivary concentration of bFGF varies with age, with the highest levels among young individuals and low levels in elderly. Since the bFGF has a key role in the maintenance of mucosal integrity, these values may reflect the age-dependent mucosal degeneration in the upper digestive tract ${ }^{27}$.
A recent study of Maciejczyk et al. evaluated the efficiency of antioxidant systems in non-stimulated and stimulated saliva and in blood samples of healthy individuals of different ages, finding a progressive weakening in the elderly. In physiological conditions, an increased production of free radicals is compensated by antioxidant systems, which prevent oxidative damage to cellular components. However, a long-term overproduction of oxygen free radicals disturbs the redox balance, in favour of oxidation reactions in intracellular lipids, proteins and nucleic acids. These processes play a key role in the pathogenesis of many diseases as well as in the aging process ${ }^{28}$.

\section{EFFECT OF SALIVARY CHANGES ON FOOD FLAVOUR PERCEPTION IN OLDER ADULTS}

It is well recognized that the taste sensitivity decreases with age ${ }^{29}$. Some studies performed on mice found a reduction in the number of taste buds as a function of age ${ }^{21}$. Conversely, other researchers rather relate the decreased taste sensitivity to a time lag in the turnover of taste receptor cells in the elderly.

In 2010, Kennedy et al. found significant differences in both detection and recognition thresholds and the correct identification of the basic taste of sweetness between young and older adults ${ }^{29}$. It is well known that the sweetness perception is $\mathrm{pH}$-dependent. As the food components need to be dissolved within the saliva to reach the taste receptors, changes in salivary inorganic composition resulting in salivary $\mathrm{pH}$ changes, may elevate the taste thresholds and decrease supra-threshold intensities. This may explain the taste aberrations and might consequently affect food intake in elderly ${ }^{21}$. However, the age-associated taste impairment results less profound than the olfactory impairment ${ }^{30}$.

\section{INFLUENCE OF MEDICATIONS ON TASTE}

The taste sensation, as well as the olfaction, may be modified by medicinal use, as shown in Tables I and II. The high prevalence of chronic diseases in the elderly is responsible for polypharmacy, i.e. use of multiple medications. Hundreds of drugs have been reported to induce unpleasant tastes and/or odours as well as altered chemosensations; other medications affect the salivary secretion through an anticholinergic activity. The chemosensory side effects of drugs are due to the properties of the drug itself, such as molecules inducing bitter or metallic taste, or more frequently to their interaction with biochemical targets, with consequent alterations in the transduction pathway.

With chronic use, drugs can accumulate into the taste buds to levels high enough to induce a bitter taste ${ }^{31}$. The accumulation is also due to hyposalivation which 
Table I. Drugs inducing taste disorders.

\begin{tabular}{|c|c|}
\hline Drug class & Drug \\
\hline Antihistamines agents & Loratadine \\
\hline Anti-inflammatory and analgesic agents & $\begin{array}{c}\text { Aspirin } \\
\text { Diclofenac } \\
\text { Ibuprofen } \\
\text { Tramadol }\end{array}$ \\
\hline Antilipidemics & Simvastatin \\
\hline Cardiovascular agents & $\begin{array}{c}\text { Furosemide } \\
\text { Hydrochlorothiazide } \\
\text { Lisinopril } \\
\text { Losartan } \\
\text { Metoprolol } \\
\text { Propranolol } \\
\text { Spironolactone } \\
\text { Triamterene }\end{array}$ \\
\hline CNS drugs & Amphetamine \\
\hline Endocrine and diabetes drugs & $\begin{array}{c}\text { Glipizide } \\
\text { Insulin } \\
\text { Metformin }\end{array}$ \\
\hline Gastrointestinal drugs & $\begin{array}{c}\text { Omeprazole } \\
\text { Ranitidine }\end{array}$ \\
\hline Psychopharmacologic agents & $\begin{array}{c}\text { Amitriptyline } \\
\text { Bupropion } \\
\text { Citalopram } \\
\text { Fluoxetine } \\
\text { Paroxetine } \\
\text { Sertraline } \\
\text { Trazodone } \\
\text { Venlafaxine } \\
\text { Alprazolam } \\
\text { Clonazepam } \\
\text { Diazepam } \\
\text { Zolpidem }\end{array}$ \\
\hline Pulmonary agents & Albuterol \\
\hline
\end{tabular}

Table II. Drugs inducing taste and smell disorders.

\begin{tabular}{|l|c|}
\hline \multicolumn{1}{|c|}{ Drug class } & Drug \\
\hline \multirow{2}{*}{ Antihypertensives } & Amlodipine \\
& Diltiazem \\
& Enalapril \\
\hline & Amoxicillin \\
Anti-infectives & Azithromycin \\
& Ciprofloxacin \\
\hline & Atorvastatin \\
Antilipidemics & Lovastatin \\
& Pravastatin \\
\hline Corticosteroids & Fluticasone \\
\hline Endocrine drugs & Levothyroxine \\
\hline
\end{tabular}

physiologically occurs in the elderly. In addition, hyposalivation can be amplified by xerostomia-inducing medications, such as psychotropic and diuretic agents ${ }^{32}$.

\section{EFFECT OF RADIOTHERAPY AND CHEMOTHERAPY ON TASTE PERCEPTION}

The chemosensory system is more vulnerable to cytotoxic chemotherapy drugs than other sensory systems, probably due to the fast renewal of the gustatory and olfactory cells. In addition to these physiological changes, cognition is also altered: patients exhibit difficulties in gustatory and olfactory recognition and overall hedonic appreciation ${ }^{33}$. As concerns patients with head and neck cancer, radiotherapy can lead to taste disturbances even when the irradiation field is not focused on the oral cavity. The most affected gustatory cells result to be those responsible for the detection of sweet, bitter, and sour sensations. Interestingly, the gustatory disturbances seem to be a consequence of the radiation-induced apoptosis in the taste buds, rather than xerostomia. A 2019 study revealed that patients who underwent radiotherapy for head and neck cancer returned to a normal gustatory function three months after radiotherapy, even though they continued to report xerostomia ${ }^{34}$.

\section{CONCLUSIONS}

Aging affects smell and taste perception for several reasons. With age, physiological changes in nasal mucosa and salivary glands lead to their progressive hypofunction. Several systemic diseases such as diabetes, hypertension and Sjogren's syndrome, and radio-chemotherapy can compromise blood perfusion and are responsible for histological damage. Senile smell and taste loss is also due to a decline in cognitive function, a decreased number of receptors, and a reduced secretory stimulation by the ANS with age. All these factors may expose the elderly people to the risk of malnutrition, due to a reduced nutrient intake, and to life-threatening situations. We retain that more efforts should be undertaken in the scientific field to safeguard the elderly people and their health.

\section{References}

1 Mazzatenta A, Carluccio A, Robbe D, et al. The companion dog as a unique translational model for aging. Semin Cell Dev Biol 2017;70:141-53. https://doi.org/10.1016/j. semcdb.2017.08.024

2 MazzatentaA, Cellerino A, Origlia N, et al. Olfactory phenotypic expression unveils human aging. Oncotarget 2016;7:19193200. https://doi.org/10.18632/oncotarget.8393

3 Ho J, Chan K, Hu W, et al. The effect of aging on nasal mucociliary clearance, beat frequency, and ultrastructure of respiratory cilia. Am J Respir Crit Care Med 2001;163:9838. https://doi.org/10.1164/ajrccm.163.4.9909121

4 Hong S, Han B, Lee S, et al. Age-related differences in the pathogenesis of chronic rhinosinusitis. J Allerg Clin Immunol 
2012;129:858-60. https://doi.org/10.1016/j.jaci.2011.12.002

5 Lee J, Lee S. Influence of age on the surgical outcome after endoscopic sinus surgery for chronic rhinosinusitis with nasal polyposis. Laryngoscope 2007;117:1084-9. https:// doi.org/10.1097/MLG.0b013e318058197a

6 Gelardi M, Piccininni K, Quaranta N, et al. Olfactory dysfunction in patients with chronic rhinosinusitis with nasal polyps is associated with clinical-cytological grading severity. Acta Otorhinolaryngol Ital 2019;39:329-35. https:// doi.org/10.14639/0392-100X-2426

7 Rodriguez K, Rubinstein E, Ferguson B. Clear anterior rhinorrhea in the population. Int Forum Allergy Rhinol 2015;5:1063-7. https://doi.org/10.1002/alr.21583

8 Bende M. Blood flow with 133Xe in human nasal mucosa in relation to age, sex and body position. Acta Otolaryngol Ital 1983;96:175-9. https://doi. org/10.3109/00016488309132889

9 Doty R, Kamath V. The influences of age on olfaction: a review. Front Psychol 2014;5:20. https://doi.org/10.3389/ fpsyg.2014.00020

10 Wilson R, Yu L, Schneider J, et al. Lewy bodies and olfactory dysfunction in old age. Chem Senses 2011;36:36773. https://doi.org/10.1093/chemse/bjq139

11 Hedner M, Nilsson L, Olofsson JEA. Age-related olfactory decline is associated with the BDNF Val66met polymorphism: evidence from a population based study. Front Aging Neurosci 2010;2:24. https://doi.org/10.3389/fnagi.2010.00024

12 Calhoun-Haney R, Murphy C. Apolipoprotein epsilon4 is associated with more rapid decline in odor identification than in odor threshold or Dementia Rating Scale scores. Brain Cogn 2005;58:178-82. https://doi.org/10.1016/j. bandc.2004.10.004

13 Corder EH, Saunders AM, Strittmatter WJ, et al. Gene dose of apolipoprotein E type 4 allele and the risk of Alzheimer's disease in late onset families. Science 1993;261:921-3. https://doi.org/10.1126/science.8346443

14 Philpott C, Bennett A, Murty G. A brief history of olfaction and olfactometry. J Laryngol Otol 2008;122:657-62. https://doi.org/10.1017/S0022215107001314

15 Mazzatenta A, Pokorski M, Di Giulio C. Real time analysis of volatile organic compounds (VOCs) in centenarians. Respir Physiol Neurobiol 2015;209:47-51. https://doi. org/10.1016/j.resp.2014.12.014

16 Mazzatenta A, Pokorski M, Sartucci F, et al. Volatile organic compounds (VOCs) fingerprint of Alzheimer's disease. Respir Physiol Neurobiol 2015;209:81-4. https://doi. org/10.1016/j.resp.2014.10.001

17 Mazzatenta A, Pokorski M, Montinaro D, et al. Chemoresponsiveness and breath physiology in anosmia. Adv Exp Med Biol 2015;837:35-9, 2015. https://doi. org/10.1007/5584_2014_66

18 Mazzatenta A, Di Giulio C, Pokorski M. Pathologies currently identified by exhaled biomarkers. Respir Physiol Neurobiol 2013;187:128-34. https://doi.org/10.1016/j.resp.2013.02.016

19 Invitto S, Mazzatenta A. Olfactory event-related potentials and exhaled organic volatile compounds: the slow link between olfactory perception and breath metabolic response. A pilot study on phenylethyl alcohol and vaseline oil. Brain Sciences 2019;9:84. https://doi.org/10.3390/brainsci9040084

20 Murphy C, Schubert C, Cruickshanks K, et al. Prevalence of olfactory impairment in older adults. JAMA 2002;288:2307-12. https://doi.org/10.1111/ggi.13621

${ }_{21} \mathrm{Xu} \mathrm{F}$, Laguna L, Sarkar AA. Aging-related changes in quantity and quality of saliva: where do we stand in our understanding? J Text Stud 2018;50:27-35.

22 Nagler R, Hershkovich O. Relationships between age, drugs, oral sensorial complaints and salivary profile. Arch Oral Biol 2005;50:7-16. https://doi.org/10.1016/j.archoralbio.2004.07.012

23 Nassar M, Hiraishi N, Islam M, et al. Age-related changes in salivary biomarkers. J Dent Sci 2014;9. https://doi. org/10.1186/s12967-018-1669-2

24 SevónL, LaineM, KarjalainenS, etal. Effect ofageonflow-rate, protein and electrolyte composition of stimulated whole saliva in healthy, non-smoking women. Open Dent J 2008;2:8992. https://doi.org/10.2174/1874210600802010089

25 Nagler R. Salivary glands and the aging process: mechanistic aspects, health-status and medicinal-efficacy monitoring. Biogerontology 2004;5:223-33. https://doi. org/10.1023/B:BGEN.0000038023.36727.50

26 Almståhl $\mathrm{A}$, Wikström M. Electrolytes in stimulated whole saliva in individuals with hyposalivation of different origins. Arch Oral Biol 2003;48:337-44. https://doi.org/10.1016/ s0003-9969(02)00200-5

27 Westermark A, Pyykkö I, Magnusson M, et al. Basic fibroblast growth factor in human saliva decreases with aging. Laryngoscope 2002;112:887-9. https://doi. org/10.1097/00005537-200205000-00020

28 Maciejczyk M, Zalewska A, Ladny J. Salivary antioxidant barrier, redox status, and oxidative damage to proteins and lipids in healthy children, adults, and the elderly. Oxid Med Cell Long 2019. https://doi.org/10.1155/2019/4393460

29 Kennedy O, Law C, Methven L, et al. Investigating age-related changes in taste and affects on sensory perceptions of oral nutritional supplements Age Ageing 2010;39:733-8. https://doi.org/10.1093/ageing/afq104

30 Murphy $\mathrm{C}$. The chemical senses and nutrition in older adults. J Nutr Elderly 2008;27:247-65. https://doi. org/10.1080/01639360802261862

31 Schiffman S. Influence of medications on taste and smell. World J Otorhinolaryngol Head Neck Surg 2018;4:84-91. https://doi.org/10.1016/j.wjorl.2018.02.005

32 Izutsu K, Treulove E, Persson G. Differences in salivary flow rates in elderly subjects using xerostomic medications. Oral Surg Oral Med Oral Pathol 1991;72:42-6. https://doi. org/10.1111/j.1754-4505.2001.tb00251.x

33 Drareni K, Dougkas A, Giboreau A, et al. Relationship between food behavior and taste and smell alterations in cancer patients undergoing chemotherapy: a structured review. Semin Oncol 2019;46. https://doi.org/10.1053/j.seminoncol.2019.05.002

34 Silva J, Doty R, Miyazaki J, et al. Gustatory disturbances occur in patients with head and neck cancer who undergo radiotherapy not directed to the oral cavity. Oral Oncol 2019;95:115-9. https://doi.org/10.1016/j.oraloncology.2019.06.008 